\title{
LYAPUNOV-TYPE INEQUALITIES FOR NONLINEAR DIFFERENTIAL EQUATION WITH HILFER FRACTIONAL DERIVATIVE OPERATOR
}

\author{
YOUYU WANG AND QICHAO WANG
}

Abstract. In this work, we establish Lyapunov-type inequalities for the fractional boundary value problems with Hilfer fractional derivative operator, the results of this paper are new and generalize and improve some early results in the literature.

Mathematics subject classification (2010): 34A40, 26A33, 34B05.

Keywords and phrases: Fractional differential equation, Lyapunov-type inequalities, fractional integral boundary conditions, Hilfer fractional derivative operator.

\section{REFERENCES}

[1] R. C. BRown, D. B. Hinton, Lyapunov inequalities and their applications, in Survey on Classical Inequalities, T. M. Rassias, Ed., Kluwer Academic Publishers, Dordrecht, The Netherlands, 2000, $1-25$.

[2] S. Cheng, Lyapunov inequalities for differential and difference equations, Fasc. Math. 23 (1991) $25-41$.

[3] S. DHAR, Q. Kong AND M. MCCABE, Fractional boundary value problems and Lyapunov-type inequalities with fractional integral boundary conditions, Electron. J. Qual. Theory Differ. Equ. (2016), no. $43,1-16$.

[4] R. A. C. FERreira, A Lyapunov-type inequality for a fractional boundary value problem, Fract. Calc. Appl. Anal. 16, no. 4 (2013), 978-984.

[5] R. A. C. FERREIRA, On a Lyapunov-type inequality and the zeros of a certain Mittag-Leffler function, J. Math. Anal. Appl. 412, no. 2 (2014), 1058-1063.

[6] R. HilfER, Fractional calculus and regular variation in thermodynamics, in: Applications of Fractional Calculus in Physics, (Ed. R. Hilfer), World Scientific, Singapore (2000).

[7] R. Hilfer, Y. LuCHKo And Z. TOMOVSKI, Operational method for the solution of fractional differential equations with generalized Riemann-Liouville fractional derivatives, Fract. Calc. Appl. Anal. 3, 12 (2009) 299-318.

[8] M. JLELI AND B. SAMET, Lyapunov-type inequalities for a fractional differential equation with mixed boundary conditions, Math. Inequal. Appl. 18, no. 2 (2015), 443-451.

[9] A. A. Kilbas, H. M. SRivastava And J. J. Trujillo, Theory and applications of fractional differential equations, North-Holland Mathematics Studies 204 Elsevier, Amsterdam, The Netherlands, 2006.

[10] A. M. Lyapunov, Probleme général de la stabilité du mouvement, (French Translation of a Russian paper dated 1893), Ann. Fac. Sci. Univ. Toulouse 2 (1907) 27-247 (Reprinted as Ann. Math. Studies, no. 17, Princeton Univ. Press, Princeton, NJ, USA, 1947).

[11] A. TIRYAKI, Recent development of Lyapunov-type inequalities, Adv. Dyn. Syst. Appl. 5 no. 2 (2010), 231-248.

[12] Z. Tomovs KI, Generalized Cauchy type problems for nonlinear fractional differential equations with composite fractional derivative operator, Nonlinear Analysis, 7, 75 (2012) 3364-3384.

[13] H. M. SRivastava, Z. Tomovs KI, Fractional calculus with an integral operator containing a generalized Mittag-Leffler function in the kernel, Appl. Math. Comput. 211 (2009) 198-210.

[14] T. SandeV, R. Metzler, Z. Tomovs Ki, Fractional diffusion equation with a generalized RiemannLiouville time fractional derivative, J. Phys. A: Math. Theor. 44 (25) (2011), ArticleID 255203. 
[15] Z. Tomovs Ki, T. SAndev, R. Metzler, J. L. A. Dubbeldam, Generalized space-time fractional diffusion equation with composite fractional time derivative, Physica A Statistical Mechanics and Its Applications 391 (8) (2012) 2527-2542.

[16] Z. Tomovski, R. Hilfer, H. M. SRIVAstava, Fractional and operational calculus with generalized fractional derivative operators and Mittag-Leffler type functions, Integral Transf. Spec. Funct. 21 (11-12) (2010) 797-814. 